\title{
HEAT STERILIZATION OF MANGOES AND GUAVAS FOR FRUIT FLIES
}

\author{
Francisco Seín Jr., Assistant Entomologist, \\ Agricultural Experiment Station, Río Piedras, Puerto Rico.
}

Some mango varieties and apparently all guavas in Puerto Rico are infested by fruit flies and thus all mango and guava varieties are excluded from exportation to the United States. There is practically no demand for guava fruits, but the present limited demand for mangoes would probably increase as that fruit became better known.

Mangoes and guavas are excluded under quarantine regulation No. 58 established in 1925 on the basis of infestation by the West Indian fruit fly, Anastrepha fraterculus Wiedeman.

According to Greene (1), A. fraterculus Wied., does not occur in Puerto Rico. In the opinion of the writer (2), a variety of the South American A. fraterculus Wied., occurs in Puerto Rico which he has described as $A$. fraterculus Wied., var., mombinpraeoptans. It is the one that breeds in some of the mango varieties. The species that breeds in guavas has been described by the writer (2) as A. unipuncta. According to Greene it is A. suspensa Loew. In this paper the two flies will be referred to as the species breeding in mangoes and the species breeding in guavas. Occasionally, when large numbers are reared, a few adults of the species breeding in mangoes will be found to breed also in guavas. That occurred in some of the experiments, but since it is not significant was not recorded.

The purpose of this paper is to report a series of tests under Puerto Rican conditions of the method of heat sterilization that has been used in Florida against the Mediterranean fruit fly and in Texas against the Mexican orange maggot and other fruit flies. The tests were made during the months of April, May, June and July 1934.

When the Mediterranean fruit fly was present in Florida, sterilized avocados from that State were allowed to be shipped to other parts of the country. The fruit had been grown in a regulated area outside the designated infested areas and was not infested. It was submitted to sterilization as an added precaution. 
In the case of the mangoes that have commercial value in Puerto Rico, the conditions are similar in that the varieties to be sterilized have not been found infested and do not appear to be susceptible to infestation.

The sterilization treatment as deseribed by Dr. Lee A. Strong in Administrative Instructions No. 287 (approved July 24, 1930) consists simply of "heating the fruit to a temperature of $110^{\circ} \mathrm{F}$ or above (not to exceed $112^{\circ} \mathrm{F}$ ) in the approximate center of the fruit and holding the temperature of $110^{\circ} \mathrm{F}$ or above (not to exceed $112^{\circ} \mathrm{F}$ ) for a period of eight hours".

No specifications as to the exact method or type of equipment to be used in sterilizing the fruit are prescribed. Available information indicates that a high humidity is essential for the best results and that the temperature should be maintained with as little variation as possible above the prescribed temperature of $110^{\circ} \mathrm{F}$. For keeping the fruit after the sterilization it should be cooled to a temperature around $45^{\circ} \mathrm{F}$ as soon as possible.

\section{Method of Procedure}

The method of procedure and the equipment described by Mackie (3) in California served as a basis for planing the experiments and for constructing the sterilizer.

The sterilization experiments with mangoes and guavas were conducted at the entomological laboratory of the Insular Experiment Station in a sterilizer constructed by Mr. Manuel L. Vicente, Chief of the Division of Agricultural Engineering of the Station. It consists of two sections, a chamber for the fruit provided with a thermostat, thermometer, and racks for wire netting trays, and another section consisting of a water tank, heating unit with three heat switch, fan, motor and switches. The circulation is closed. The air becomes warm and saturated with moisture by passing over the hot water and heats the fruit chamber entering at the upper part, circulating around the fruit and returning to the water tank through an opening at the lower part of the chamber.

To conduct the experiments during office hours, the sterilizer was kept running on "low" during the previous night. The fruit was introduced the next morning at 7:00 A. M. The switch was then turned to "high" and as soon as the temperature reached $43^{\circ}$ C (about $110^{\circ} \mathrm{F}$ ) changed to "low". The thermostat maintained it uniformly at $43^{\circ} \mathrm{C}$ for eight hours. 


\section{Mango VARIETIES}

There are two types of mangoes in Puerto Rico, the native seedlings and the more recently introduced selected East Indian varieties. In each type there are some varieties always infested with fruit fly maggots and others which have not been found infested at all and appear to be immune. Of the varieties that have not been found infested, the only native one that has commercial value is the "mango de Mayagüez" or Mayagüez mango. Of the recently imported varieties, the Colombo Kidney has high quality and is prolific. At Ponce there is a large grove of a variety that has been given the owner's name, Mr. Girón. In the island of Vieques there are some varieties that have commercial value. At present the only commercial variety grown on a large scale is the Mayagüez mango.

The Mayagüez mango is medium sized and attractively colored. It ships and keeps well but is very fibrous. There would be a good demand for it however, among West India residents in the United States. If the demand for mangoes higher in quality increased, they would be planted on a large scale.

\section{Only Immune Varieties Have Commercial Value}

Even in local markets, mangoes infested with fruit fly maggots have no commercial value. Their exportation to United States markets would be even less practical. Infested fruit can not be rendered marketable by sterilization because, though the maggots are killed, their dead bodies remain inside the fruits where they decompose, together with the pulp tissues previously injured by their tunneling.

The female fruit fly lays her eggs in the mangoes when green and the maggots may become full grown before the fruits are half ripe. For the mangoes to ripen properly they must be picked from the tree when at least half ripe. It would be impossible therefore to pick marketable fruit of the susceptible varieties early enough to prevent infestation.

The admission of sterilized mangoes into the United States is thus rendered doubly safe (1st) by the fact that only varieties that are not infested are marketable, and (2nd) because such sound fruit would nevertheless, and in addition, have been submitted to a treatment that kills the pest if it were present in them. 


\section{The Mango Variety Used in the Experiment}

The mango variety used in the experiments is the one known as "mango blanco" or white mango. It was not chosen for its commercial possibilities but on the contrary, for its susceptibility to fruit fly infestation. A high percentage of the fruits of this variety is always infested. Since a large number of trees grow on the Station grounds and produce very large crops, procuring the fruit at the right stage of maturity was rendered easy.

\section{The Guava Varieties Used in the Experiments}

The guava fruits used in the experiments were of the two common varieties that grow on pastures, waste lands and fence rows on the Island. The two varieties have round-shaped medium sized fruits. The fruits of one variety are sweet, those of the other are sour. High percentages of the fruits of both varieties are ordinarily infested with fruit fly maggots. That does not however, destroy their value, for they are not consumed fresh but used for making preserves and jellies. For cooking purposes, most of the maggots can be made to abandon the fruit by soaking in cold water overnight.

\section{Method of Handling the Fruit}

The half ripe mangoes and guavas used in the experiments were picked from the trees the previous day. Some showed the emergence holes of the maggots opening through the cuticle. Emergence holes indicate that some full grown larvae may have left the fruit and also that full grown larvae are present in the fruit. Each lot of fruit to be sterilized or kept as checks consisted partly of fruit with emergence holes. When the fruit had cooled off after sterilization, some having emergence holes were cut open to determine the condition of the larvae. The rest of the sterilized froits and the checks were kept under observation on moist sand. The appearance of new emergence holes was noted. When the fruits began to rot they were cut open and inspected. The sand on which they stood was then sifted for pupae.

The presence of fruit fly eggs in the half ripe mangoes can be determined by observation of the tips which protude out of the cuticle (2). The species that ordinarily infests guavas lays its eggs entirely underneath the cuticle (2). Their presence in the fruit was inferred by the fact that the infestation of maggots in the checks was about normal. 


\section{Preliminary Experiments with Mangoes}

Ten preliminary experiments were conducted using the first infested fruits of the 1934 crop which dropped from the trees and were picked from the ground in April. All showed emergence holes when collected.

After the sterilization, some dead maggots were observed on the floor of the chamber underneath the fruit. Some maggots were also found dead with their bodies partially out of the emergence holes. Cutting the fruits open, dead fruit fly maggots of various sizes were found. None was found alive. The cut open fruits were kept under observation on sand until the pulp rotted and inspected daily but no fruit fly maggots developed in them and no pupae were recovered by sifting the sand on which the fruit stood. The number of maggots found per fruit was as follows:

Number of fruits, 5_-_Number of maggots per fruit: $3,6,5,7,4$ Number of fruits, 7 -_.Number of maggots per fruit: $6,2,5,4,3,4,7$ Number of fruits, 6 -_-_Number of maggots per fruit: $3,5,6,2,8,5$ Number of fruits, 8 -_-_Number of maggots per fruit: $4,10,5,6,9,4,6,5$ Number of fruits, $12 \ldots$ Number of maggots per fruit: $3,7,5,6,9,4,6,5$, $4,8,7,6$

Number of fruits, 15_Number of maggots per fruit: 4, 10, 5, 3, 7, 4, 6, 3, $9,5,7,2,4,7,6$ Number of fruits, 8 -_.Number of maggots per fruit: $5,3,7,12,6,4,5,3$ Number of fruits, 7 -_-_Number of maggots per fruit: $6,9,5,5,4,8,6$ Number of fruits, $10 \ldots \ldots$ Number of maggots per fruit: $4,7,2,5,3,6,4,8$, 11,5

Number of fruits, 7_-_Number of maggots per fruit: 12, 6, 3, 2, 5, 4, 6 .

\section{Final Experiments}

When mangoes became abundant in the months of May, June and July 20 lots of 100 apparently infested fruits each were sterilized at different intervals keeping a lot of 100 similar fruits unsterilized as checks. The results were the following:

Experiment No. 1.-Sterilized: percentage of fruits infested_---- 0 Check-percentage of fruits infested_-_-_-_- 73

Experiment No. 2.-Sterilized: percentage of fruits infested_-_-- 0 Check-percentage of fruits infested______- 67

Experiment No. 3.-Sterilized: percentage of fruits infested Check-percentage of fruits infested______-_ 87

Experiment No. 4.-Sterilized: percentage of fruits infested_._-- 0 Check-percentage of fruits infested_-_-_-_ 70

Experiment No. 5.-Sterilized: percentage of fruits infested_---- 0 Check-percentage of fruits infested-_-_-_-- 84

Experiment No. 6.- Sterilized: percentage of fruits infested_---- 0 Check-pereentage of fruits infested_-_-_-_-- 74 
Experiment No. 7.-Sterilized: percentage of fruits infested__-_- 0 Check-percentage of fruits infested._._-_._-_ 58

Experiment No. 8.-Sterilized: percentage of fruits infested_._-_ 0 Check-percentage of fruits infested_-_-_--- 72

Experiment No. 9.-Sterilized: percentage of fruits infested_-_-- 0 Check-percentage of fruits infested_-_-_-_-- 57

Experiment No. 10.-Sterilized: percentage of fruits infested...-- 0 Check-percentage of fruits infested_-_-_-_-- 86

Experiment No. 11.-Sterilized: percentage of fruits infested_-_-- 0 Check-percentage of fruits infested_-_-_-_-- 61

Experiment No. 12.-Sterilized: percentage of fruits infested__-_- 0 Check-percentage of fruits infested_-_------ 45

Experiment No. 13.- Sterilized: percentage of fruits infested_._-_- 0 Check-percentage of fruits infested-_-_-_--- 52

Experiment No. 14.-Sterilized: percentage of fruits infested_---- 0 Check-percentage of fruits infested._-_.-.-- 80

Experiment No. 15.- Sterilized: percentage of fruits infested_-_-_ 0 Check-percentage of fruits infested__-_-_-- 71

Experiment No. 16.-Sterilized: percentage of fruits infested_---- 0 Check-percentage of fruits infested_._-_-_-_ 65

Experiment No. 17.-Sterilized: percentage of fruits infested_-_--- 0 Cheek-percentage of fruits infested._-_-_--- 42

Experiment No. 18.--Sterilized: percentage of fruits infested_-.-- 0 Check-percentage of fruits infested.--_---- 78

Experiment No. 19.--Sterilized: percentage of fruits infested_-_--- 0 Check-percentage of fruits infested_-_------ 70

Experiment No. 20.- Sterilized: percentage of fruits infested_-_--- 0 Check-percentage of fruits infested-_-_-_--- 63

Total sterilized fruits, 2,000, total infested, 0 .

Total check fruits, 2,000, total infested, 1,357, percentage infested, 67.8 .

No pupae were recovered from the sand on which the sterilizec fruits stood. From the sand on which the check fruits stood 4,03: pupae were recovered and 3,200 adults emerged from them. Thi adults were identified by the writer as the species breeding in man goes.

The sterilized fruits which were not infested, ripened normall: and showed no difference in flavor, texture, or keeping qualitie from the non-infested check fruits.

\section{Experiments with Guavas}

Ten lots of 50-half ripe apparently infested guava fruits each wer sterilized keeping ten lots of 50 similar fruits unsterilized as check

Experiment No. 1.-Sterilized: number of fruits infested.--_-_--- 0 Check-number of fruits infested_._-_._- 43

Experiment No. 2.-Sterilized: number of fruits infested._-___-_ 0 Check-number of fruits infested 
Experiment No. 3.-Sterilized: number of fruits infested_---_-_-- 0

Check-number of fruits infested_-_-_-_-_-_-- 36

Experiment No. 4.-Sterilized: number of fruits infested___._.-_- 0

Check-number of fruits infested.--_-_--- 41

Experiment No. 5.-Sterilized: number of fruits infested_-_---_--- 0

Check-number of fruits infested_-_-_-_-_-_-- 35

Experiment No. 6.-Sterilized: number of fruits infested_-_-_-_-_ 0

Check-number of fruits infested_------------ 46

Experiment No. 7.-Sterilized: number of fruits infested_--_--_--- 0 Check-number of fruits infested._._._._._._- 30

Experiment No. 8.-Sterilized: number of fruits infested_-_-_-_-_ 0

Check-number of fruits infested_-_-_-_-_-_ 40

Experiment No. 9.--Sterilized: number of fruits infested_-_-_---- 0

Check-number of fruits infested.-..-- 26

Experiment No. 10.-Sterilized: number of fruits infested___-_.--_ 0

Check-number of fruits infested.--_--------- 32

Total sterilized, 500 fruits, total infested, 0.

Total checks, 500 fruits, total infested, 361, percentage infested, 72.2.

No new emergence holes were observed in the guava fruits that were sterilized, nor were maggots found in them. No pupae were recovered from the sand on which the fruit stood. In the check fruits new emergence holes and living maggots were observed and 983 pupae were recovered from the sand on which the fruit stood. From the pupae, 840 adults emerged which were identified by the writer as the species that breeds in guavas.

\section{Sterilization iof Pupae From Mangoes}

Although the fruit fly infesting mangoes in Puerto Rico does not pupate inside the fruit, nevertheless, to determine whether the pupae would be affected in the same manner as the eggs and the maggots by the sterilization treatment, 500 pupae were placed among mango fruits and sterilized at $43^{\circ} \mathrm{C}$ for 8 hours.

The sterilized pupae as well as 500 more similar pupae which served as checks were kept in moist sand. No flies emerged from the sterilized pupae. From the checks, 423 flies emerged. They were identified by the writer as the species that breeds in mangoes.

\section{Sterilization of Pupae From Guavas}

The species breeding in guavas, is the one that occasionally infests citrus. In guavas it does not pupate inside the fruit but in citrus it occasionally does. One hundred pupae of this species were sterilized having been placed among guava fruits. No flies emerged from them. From 100 similar pupae kept as check, 76 
adults emerged which were identified by the writer as the species that breeds in guavas.

\section{Conclusions}

The tests prove that an exposure of eight hours at $43^{\circ} \mathrm{C}$ in an appropriate sterilizer is sufficient to kill the eggs, maggots and pupae of the fruit flies that infest mangoes and guavas in Puerto Rico. The treatment does not alter the flavor, texture or keeping qualities of the fruit that is not infested with fruit flies.

\section{Shortening the Sterilization Period Flor Mangoes}

To determine whether a period shorter than eight hours at $43^{\circ} \mathrm{C}$ might be sufficient, five experiments were conducted using 50 halfripe "white mango" fruits in each experiment and keeping an equal number unsterilized as checks. A total of 250 fruits were sterilized for four hours and an equal number kept as checks. None of the sterilized fruits showed new exit holes or was found to contain living fruit fly maggots. No pupae were recovered from the sand on which the sterilized fruit stood. Out of the checks, 112 fruits showed new exit holes and contained living fruit fly maggots. From the sand under the checks 305 pupae were recovered from which 235 adults emerged. They were identified by the writer as the species that breeds in mangoes.

The tests show that four hours at $43^{\circ} \mathrm{C}$ are sufficient to kill the fruit fly eggs or maggots present in mango fruits. Thus an eighthour period provides a very large margin of safety.

\section{Shortening the Sterilization Period For Guavas}

Five more experiments similar to the previous were conducted using 50 half-ripe guavas in each and keeping 250 similar fruits unsterilized as checks. None of the fruits treated for four hours showed fresh exit holes or was found to contain living fruit fly maggots. No pupae were recovered from the sand underneath them. Out of the 250 fruits kept as checks 186 showed new exit holes and contained living fruit fly larvae. From the sand under the checks 460 pupae were recovered from which 340 adults emerged. The adults were identified as the species breeding in guavas.

The tests show that with the species breeding in guavas, the sterilization period can also be shortened without reducing its effectiveness and that therefore the eight-hour period offers a large margin of safety. 


\section{Sterilization of Mangoes Wrapped in Paper}

To determine whether eight hours at $43^{\circ} \mathrm{C}$ would be sufficient to kill the eggs or maggots of the fruit fly in mangoes that have been wrapped in paper similar to that used for packing citrus fruits, 50 fruits were used in each of five experiments, keeping 50 similar fruits as checks. None of 250 sterilized fruits showed new exit holes or was found to contain living fruit fly maggots. No pupae were recovered from the sand under them. Out of 250 . check fruits 92 showed new exit holes and were found to contain fruit fly maggots. From the sand under them 340 pupae were recovered and 194 adults emerged. The adults were identified by the writer as the species that breeds in mangoes.

The results of the experiments show that mangoes can be successfully sterilized after having been wrapped in paper.

\section{Sterilization of Mangoes Packed in Crates}

To determine whether 8 hours at $43^{\circ} \mathrm{C}$ would be sufficient to kill the eggs and maggots of the fruit fly in mangoes packed in crates, five experiments were conducted. Thirty half-ripe "white mango" fruits were used in each experiment keeping 30 similar fruits for checks. Three kinds of crates were used: (1) all sides $1 / 2$ inch white pine wood, (2) bottom and two sides $1 / 2$ inch white pine wood other two sides and top wire netting and (3) all sides $1 / 2$ inch white pine wood with an opening 2 inches square covered with wire netting on each side except top and bottom. Ten mangoes were placed in each crate and sterilized. The experiment was repeated five times. The total number of fruits sterilized was 150 . No new emergence holes, nor living fruit fly maggots were found in them and no pupae in the sand underneath them. Out of 150 check fruits, 93 showed new emergence holes or were found to contain living fruit fly maggots and 240 pupae were recovered from the sand under the fruits. From the pupae 146 adults emerged which were identified by the writer as the species that breeds in mangoes.

These experiments show that mangoes packed in crates similar to those used commercially for fruits and vegetables can be sterilized to kill eggs or maggots of the fruit fly as readily as if the mangoes were placed on trays.

\section{Sterilization of Mangoes Wrapped and Crated}

To determine whether mangoes wrapped in paper, packed 'in crates and sterilized for 8 hours at $43^{\circ} \mathrm{C}$ would have the eggs and 
maggots of the fruit fly killed, 5 experiments were conducted which were a repetition of the previous one excepting that the fruits before crating were wrapped in tissue paper sheets similar to those used for citrus. No new emergence holes nor fruit fly maggots were found in any of the 150 sterilized fruits and no pupae in the sand underneath them, but of 150 fruits kept as checks, 103 showed new emergence holes or were found to contain living fruit fly maggots and 327 pupae were recovered from the sand underneath them.

These experiments show that mangoes wrapped in paper and packed in crates similar to those used for other fruits and vegetables could be sterilized successfully.

\section{Summary}

1. Mango fruits infested with fruit fly maggots have no commercial value and could not profitably be shipped to the United States.

2. Sterilization at a temperature of $43^{\circ} \mathrm{C}$ for eight hours in a circulating atmosphere saturated with moisture kills the eggs, maggots and pupae of the fruit flies that infest mangoes and guavas in Puerto Rico without unfavorably affecting the flavor, appearance or keeping qualities of the fruit if it is afterwards placed in refrigeration.

3. Sterilization does not render marketable mangoes which have already been injured by fruit fly maggots. Such fruit shows the injury and the dead maggots on being cut open, and decays rapidly.

4. Sterilized mangoes from Puerto Rico could safely be allowed into the United States under permit because (1st) only varieties that are not infested would be shipped and (2nd) the fruits would in addition have been submitted to a treatment which renders them free from the pest if they contained it.

5. The varieties that could be sterilized are the Mayagüez mango, the Girón, the Colombo kidney and some of the better ones from Vieques.

6. Since the period of sterilization of eight hours can be reduced to four hours without rendering the treatment less effective in destroying the insect, the margin of safety is very large.

7. Mangoes can be rendered free from fruit fly infestation by sterilization for 8 hours at $43^{\circ} \mathrm{C}$ piled on trays, crated or wrapped in paper and crated. 
HEAT STERILIZATION OF MANGOES AND GUAVAS FOR FRUIT FLIES 115

\section{Literature Cited}

1. Greene, C. T. A revision of the genus Anastrepha based on a study of the wings and the length of the ovipositor sheath (Diptera: Trypetidae). Proc. Ent. Soc. Wash. 36(6): 127179, Tllus. July 9, 1934.

2. Sein, Francisco Jr. Anastrepha (Trypetidae, Diptera) fruit flies in Puerto Rico. Jour. Dept. Agric. Puerto Rico, 17(3) : 83196, Illus. Nov. 14, 1933.

3. Mackie, D. B. Heat treatment of California fruits from the standpoint of compatibility of the Florida process. Monthly Bul. Dept. Agr. Calif. 20(3) : 211-218, Illus. 1931. 